\title{
Oral versus written assessments: a test of student performance and attitudes
}

Mark Huxham*, Fiona Campbell and Jenny Westwood

Student performance in and attitudes towards oral and written assessments were compared using quantitative and qualitative methods. Two separate cohorts of students were examined. The first larger cohort students $(n=99)$ were randomly divided into 'oral' and 'written' groups, and the marks that they achieved in the same biology questions were compared. Students in the second smaller cohort $(n=29)$ were all examined using both written and oral questions concerning both 'scientific' and 'personal development' topics. Both cohorts showed highly significant differences in the mean marks achieved, with better performance in the oral assessment. There was no evidence of particular groups of students being disadvantaged in the oral tests. These students and also an additional cohort were asked about their attitudes to the two different assessment approaches. Although they tended to be more nervous in the face of oral assessments, many students thought oral assessments were more useful than written assessments. An important theme involved the perceived authenticity or 'professionalism' of an oral examination. This study suggests that oral assessments may be more inclusive than written ones and that they can act as powerful tools in helping students establish a 'professional identity'.

Keywords: oral assessment; authenticity; identity; performance; inclusive

\section{Introduction}

The oral examination (or viva voce), in which the candidate gives spoken responses to questions from one or more examiner, is perhaps the oldest form of assessment; it has certainly been traditional practice in some areas of academic life, such as the Ph.D. viva and clinical examination, for decades if not centuries. But, despite this antiquity it is now rare or absent in many undergraduate courses. For example, Hounsell et al. (2007) reviewed the recent UK literature on 'innovative assessment'. Of 317 papers considered, only 31 dealt with 'non-written assessments', and within this category only $13 \%$ addressed the use of oral examinations; oral group presentations were by far the most commonly cited non-written assessment, at $50 \%$ of the total sample.

The apparent rarity of the oral examination is surprising given its many possible advantages. Five suggested key benefits are: first, the development of oral communication skills. These are seen as essential for graduates, which means these skills must be explicitly taught and assessed (Wisker 2004). Second, oral examinations are more authentic than most types of assessment (Joughin 1998). Virtually all graduates will attend job interviews, and will have to defend their ideas and work in verbal

*Corresponding author. Email: m.huxham@napier.ac.uk 
exchanges, whilst most will never sit another written examination after they graduate. Third, oral assessment may be more inclusive. For example, Waterfield and West (2006) report the views of 229 students with disabilities on different types of assessment. Written exams were the least preferred type, whilst oral examinations consistently came near the top; students with dyslexia were particularly likely to favour oral assessments. Fourth, oral examinations are powerful ways to gauge understanding and encourage critical thinking (Gent, Johnston, and Prosser 1999). Because of the possibility of discourse and genuine exchange, oral examinations can allow a focus on deep understanding and critique, rather than on the superficial regurgitation often found in written examinations. Fifth, oral examinations are resistant to plagiarism (Joughin 1998); students must explain their own understanding using their own words.

In addition to these advantages, there is a deeper dimension to oral assessment that involves fundamental distinctions between oral and written communication. The philosopher Frege emphasised the ambiguity and fluidity of language, and discussed how the ability of spoken, as opposed to written, language to carry emotional charge allowed it a flexibility and finesse not possible on the written page (Carter 2008). This reflects a long-held position in philosophy, going back at least to Plato, that elevates the spoken word above the 'mere shadow' that is the written (Joughin 1999). The idea that speech reflects, and creates, the person more accurately and fully than writing has been developed more recently by Barnett, who considers how students struggle in the 'risky' environment of higher education to find new ways of defining themselves: 'speech is one way in which individuals help to form their own pedagogical identities. It has an authenticity that writing cannot possess' (Barnett 2007, 89). Related to these ideas is the pervasive and important notion that higher education at its best consists of dialogue and learning conversation. To adapt a phrase from psychoanalysis, teaching is 'an alchemy of discourse' (Hayes 2009) from which new understandings can arise. Hence there are fundamental reasons why higher education might value oral assessments.

So why, despite these arguments, might oral examinations be rare? One obvious reason could be the perception that they take a long time; individual interviews with 300 first years will generally be impossible (although it is worth considering the possible savings in time gained from not marking written work). But there is a more explicit concern about reliability and bias. For example, Wakeford (2000) advises: 'The new practitioner in higher education is counselled to beware of and avoid orals', since they may be open to bias; clearly, for example, anonymous assessment will be impossible and producing evidence for external examiners is more difficult. There is a concern too that oral examinations are very stressful, and might unfairly favour the extravert and confident student (Wisker 2004). They are often seen as an 'alternative approach' which might be valid for a minority of disabled students but which should not apply 40 to the majority (Waterfield and West 2006). In addition, oral examinations may be seen as suitable for assessing more emotive or personal issues, such as the ability to reflect, but as not appropriate for abstract reasoning: 'only an exceptional person would prefer to be judged on the basis of a spoken rather than written performance when the assessment relates to complex abstract ideas' (Lloyd et al. 1984, 586).

Hence despite the strong arguments in favour of oral examinations, tutors might legitimately fear using them given pressures on time, warnings that they may not reach transparent standards of reliability and may be biased against some students and feelings that they are only for 'special' groups. There is currently little in the literature that might help a balanced assessment of the strengths and weaknesses of 
oral versus written assessments (but see Joughin 2007). For example, there are to our knowledge no explicit tests of performance in the same examination administered orally and in writing to higher education students. The main aim of the current work is to help fill this gap by performing such a test. In addition, we considered the following questions: (1) Do the results in oral and written examinations differ between different types of questions (in particular, between abstract 'scientific' questions and those requiring reflection on personal skills)? (2) Do students find oral assessments more stressful than written assessments? (3) What do students feel are the strengths and weaknesses of oral versus written assessments?

\section{Methods}

\section{Student groups}

Three groups of students were involved as participants in this research. The largest group was a first-year (Level 7) cohort of 99 biology students taking an introductory module in evolutionary biology, $28 \%$ of whom were male and who ranged in age from 17 to 45 (with a majority in the 17-20-year age group). The second group included 29 third-year (Level 9) students taking a field methods module, with eight males, ranging in age from 18 to 42 . The third group included 18 third-year students, seven of whom were males and ranging in age from 19 to 29 , who studied the same field methods module the previous year.

\section{Randomised test}

In October 2007 the first-year students were randomly allocated to either a 'written' or an 'oral' group. Students were told of their allocation four weeks before the assessment, which was a small formative test designed to encourage review and revision of module material before major summative assessments. After explaining the purpose of the division into two groups, students were told that they could request a change of group if they wished. The test involved seven short-answer questions that were taken from a list of 'revision points' that students had already seen after lectures. Questions dealt with evolution and ecology and were intended to test for understanding rather than recall; for example, question two was: 'What explanation can you give for the fact that most wild plants have even, as opposed to odd, numbers of chromosomes?', whilst question three asked: 'Birds and bats share the analogous similarity of wings. What is meant by this phrase, and what has caused the similarity?'. Students allocated to the 'written' group were given 30 minutes to answer the questions under standard, silent examination conditions. Students allocated to the 'oral' group had a maximum of 15 minutes in a one-to-one oral examination. The additional time allowed for the written test was to compensate for the relative slowness of writing compared with talking; experience in previous years had shown that the time allocated was more than sufficient for full answers in both formats. A team of 10 volunteer interviewers was involved. All the candidates came to a single room before their designated interview slot, and they were accompanied from there to the interview room to prevent any opportunity of speaking with previous candidates before the test. Interviewers followed a standard interview protocol; questions were read out and were repeated if the candidate asked. Interviewers were also permitted to clarify questions if asked, but only by re-phrasing rather than by interpreting the question - appropriate clarification was discussed 
between interviewers during training sessions before-hand. Interviewers also endeavoured to generate a friendly and relaxed atmosphere.

Questions in the written and oral tests were marked on a scale of 0 (no answer or completely wrong), 1 (partially correct) or 2 (correct and including all key points); hence the maximum score was 14. Interviewers had standard marking sheets and had discussed all the questions together before the interviews; they made short relevant notes during the interview and then produced a final mark immediately afterwards, before the next candidate arrived. Written questions were double-blind marked. At the end of the written test and of each interview, all students were asked to complete a very simple questionnaire with the single question 'how nervous were you about taking this test?'(answers from 0 'not at all nervous' through 4 'very nervous').

Mean scores were compared between 'written' and 'oral' groups using a $t$-test (after testing for normality and heteroscedasticity). The distributions of responses to the 'nerves' questionnaire were compared using a chi-squared test.

\section{Paired test}

An oral examination with four questions - two 'scientific analysis' questions on a field report submitted by the candidate and two 'personal and professional development' questions asking for reflection on, for example, communication and group work skills developed and used during the fieldwork - is the most important assessment component in the 'applied terrestrial ecology' module taken by the third-year cohort. Questions are specific to each candidate and are developed based on each individual's report and field performance. The usual test was modified in 2008 by the addition of a written element, involving two additional questions (one 'scientific analysis' and one 'personal and professional development'). Questions were first devised for each candidate and then selected at random for the oral or written component. All candidates were taken initially to an examination room where they had eight minutes to complete the written questions, before being led to the interview room for a 15-minute oral examination.

In these interviews, the assessor quickly promoted a positive and friendly environment for the each student by providing a warm welcome, establishing a rapport through use of their first names, clarifying what was to happen in the oral assessment and thanking them for their report. The questions asked had a clear context (e.g. they referred to a specific figure or table in the student's field report) and where students did not fully answer questions, they were asked another supplementary - although not leading - question (e.g. if a student was asked 'why did you choose to use an ANOVA test for the data in Table 2?' a supplementary question might be 'under what general circumstances do you use ANOVA?').

Questions were marked on a seven-point scale $(0=$ no response, $3=$ bare pass, showing a very basic understanding but no knowledge of the broader context or evidence of wider reading and synthesis of knowledge from elsewhere, $6=$ excellent answer, showing clear understanding and an ability to place the answer in a broad context of relevant literature or experience); one-third of the oral examinations were double marked by two interviewers, and all written questions were double marked. Mean scores (out of the total of four questions in the oral and two in the written tests) were compared, paired within candidates, using a paired $t$-test. Marks were also subdivided into those for 'scientific analysis' and 'personal and professional development' 
questions, and mean marks achieved in the oral and written tests for these were compared using paired tests.

\section{Qualitative evaluation}

Three different sets of qualitative data were collected. First, students from the firstyear cohort were invited to participate in a focus group to discuss their experiences. The discussion was facilitated by a member of staff from outside the programme team and students were advised that staff involved in the module would not be present. Equal number of students who had experienced the written and oral tests participated and different student groups were invited including home, international, schoolleavers, mature students, and males and females. The discussion was recorded and students participating gave permission for their contributions to be used on the basis that their input would be anonymous. To encourage participation, the invitation made clear that their input was valued; they were also offered a sandwich lunch.

Qualitative feedback was collected from the third-year cohort in 2007, who took an oral assessment identical to that described for the 2008 cohort but without the addition of the written component. This is the first time these students had experienced this kind of viva voce test at university. After the tests had been marked and feedback had been provided, students were asked by email to respond to the following statement:

Please describe how you felt the interview went. In particular, how did you perform compared to a more conventional assessment (such as a written exam)? What do you think the advantages and disadvantages of being assessed by interview are, and what lessons can you learn from the experience?

Students in the third-year cohort in 2008 were also invited to participate in a focus group to discuss their experiences of the viva voce. The focus group ran on the same basis as that described for first-year students above.

Recordings from the focus groups were transcribed, and thematic analysis was used on these transcripts and on the email texts to identify key themes and illustrative quotes.

\section{Results}

\section{Randomised test}

Four students requested transfers from the group to which they had randomly been assigned; two non-native English speakers asked to be moved from the oral to the written examination. Two students also asked to transfer from the written to the oral group; one on the grounds of dyslexia and one for undisclosed reasons.

A total of 91 students took the assessments ( 45 sat the oral examination and 46 the written one). The mean scores achieved in the oral and written tests were 8.17 and 6.24 respectively, a highly significant difference (two-sample $t$-test: $t$-value $=3.46$, df $=89, P$-value $=0.001$; Figure 1$)$. Separating by gender gave a highly significant difference between females, with a difference of 2.03 between mean scores. Males showed a similar trend, with orally assessed students doing better by 1.50 marks on average, however this was not significant (two-sample $t$-test: $t$-value $=1.39, \mathrm{df}=26$, $P$-value $=0.176$ ). There was no significant difference in the marks given by the two independent markers to the written test results. 


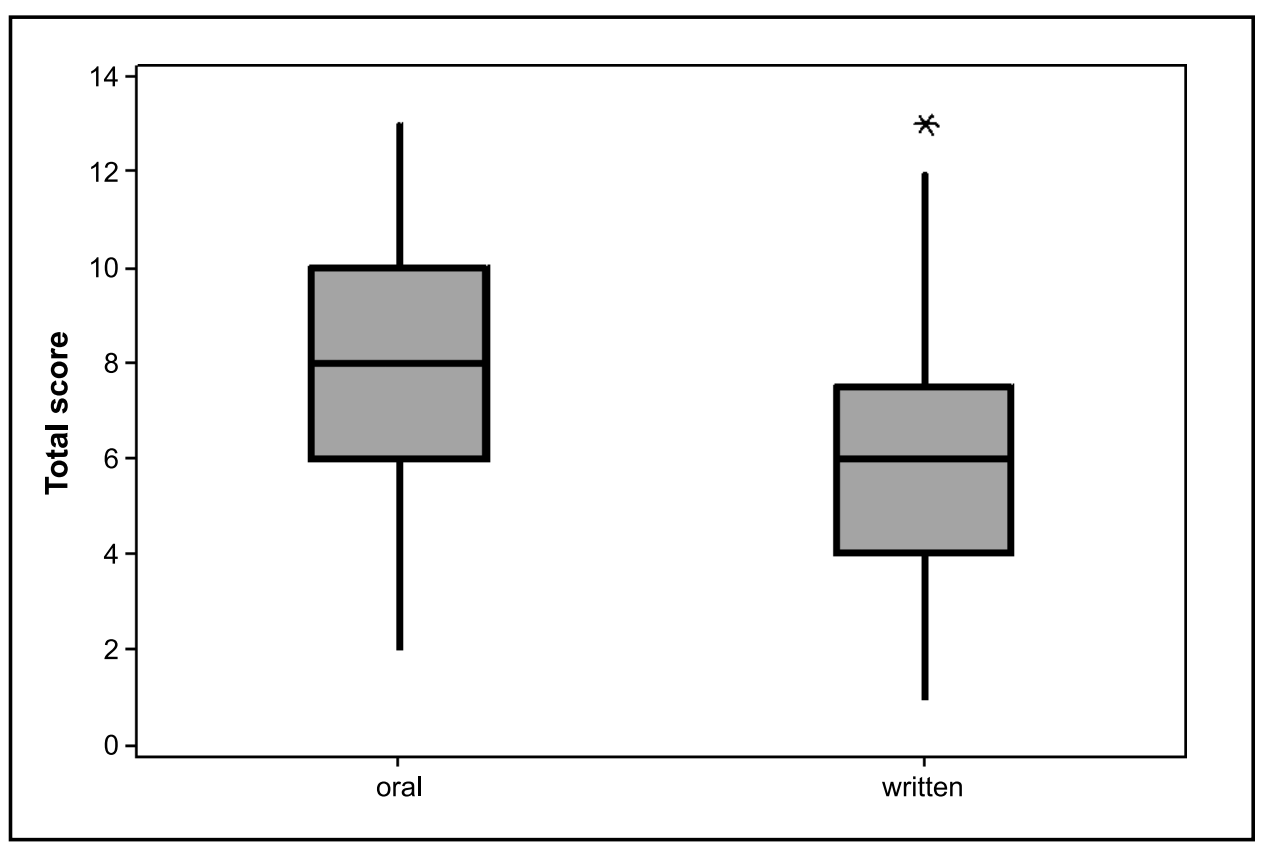

Figure 1. Boxplots (showing medians, central line, interquartile range, box margins and outliers) of data obtained from the first-year students' results in oral $(n=45)$ and written $(n=46)$ tests.

The distributions of scores recorded in the 'nerves' questionnaire are shown in Figure 2. There was a tendency for students to record higher scores (i.e. a greater degree of nervousness) in the oral group, although this was not quite a significant difference (chi-squared test: $\mathrm{chi}-\mathrm{Sq}=6.778, \mathrm{df}=3, P$-value $=0.079)$.

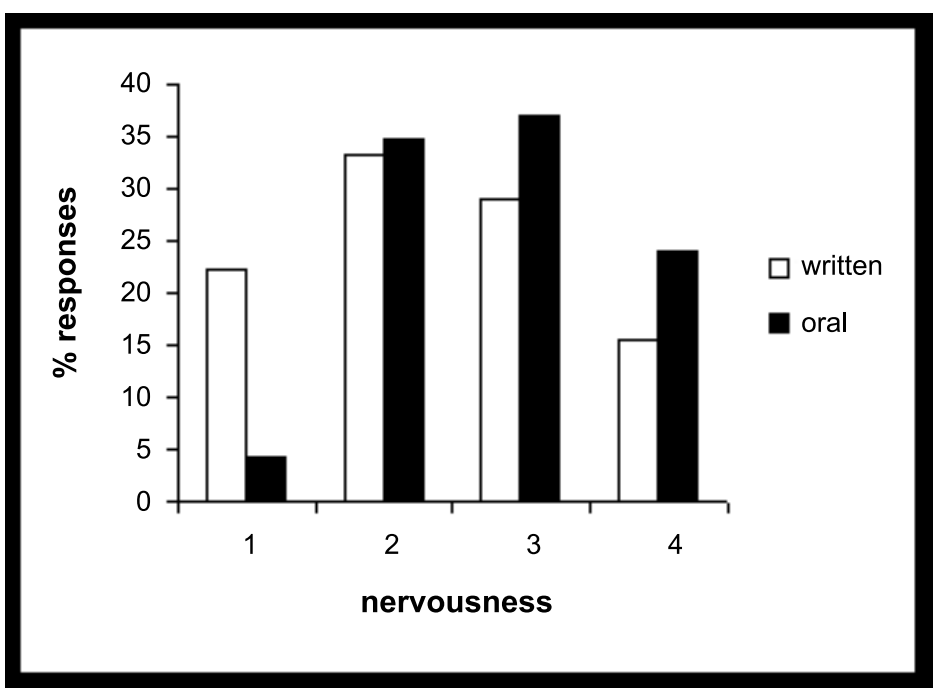

Figure 2. Frequency distributions of self-reported 'nervousness' of first-year students who took the oral and written tests; $1=$ 'not at all nervous', $4=$ 'very nervous'. 


\section{Paired test}

Twenty-four students completed the oral and written tests. There was a highly significant difference between the marks scored by each student in the oral $($ mean $=5.4)$ and written (mean $=4.6$ ) components (paired $t$-test: $t=3.84, P=0.001$ ). The better performance in the oral assessment was consistent between question types with the significant differences remaining for both the subsamples of 'scientific analysis' and 'personal and professional development' questions.

\section{Qualitative evaluation}

Fifteen (out of a total of 18) third-year students responded to the email request for feedback in 2007 (comments from this group are henceforth indicated by '3rd 2007'). In common with similar work seeking to capture the student voice (Campbell et al. 2007), recruiting participants for the focus groups proved problematic and only three first-year students (comments indicated by '1st 2008') and four third-year students (3rd 2008) attended their respective groups. However those who did attend contributed their views enthusiastically and perceptively.

An important theme in the student responses concerned anxiety; seven students in the 2007 cohort mentioned feeling particularly nervous in the face of the interview, and this was also raised in the focus groups:

I felt I did poorly in the oral exam, however I can honestly say that much of this was down to nerves. I felt uncomfortable and was concentrating so hard on trying to sound professional and not make mistakes. (3rd 2007)

You had to think [quickly] and then you are thinking you will be short on time and so you panic. (3rd 2008)

However, two students in 2007 and two in the focus groups said they felt less nervous than in written examinations. Students also identified interviews as challenging because they required real understanding:

In comparison to a conventional exam I thought it was just as challenging, if not a little
more. To be able to cram for an exam and put it all down on a piece of paper is one thing,
but to be able to talk about a subject, clearly and concisely, you have to really understand
it, and I think that is the challenge in an interview. (3rd 2007)
You need to understand what you are saying, what you are trained to explain. (3rd 2008)

Despite the reported anxiety, 13 of the students stated explicitly that they preferred the oral examination to a traditional written one, whilst only four stated that they would have preferred a written test. Most of the students valued the opportunity to practice interview skills and gain relevant experience:

I think having an assessed interview is a good idea. It give me an insight into what I'll inevitably have to deal with in the future, interview skills don't come naturally so I think the more practice we get the better equipped we'll be for leaving university and applying for jobs. (3rd 2007)

One student described preferring an interview because he was dyslexic.

An additional theme concerned how easy it was to express thoughts and opinions in the two formats, with some students identifying oral communication as more 'natural': 
I did keep thinking back, thinking 'they are next door saying what they mean and I am struggling to put down on paper'. (1st 2008)

I thought it was easier to explain yourself and explain what you are doing to a person rather than trying to [write it down]. Its easy to get muddled up with your words and try to explain something in writing. If you talk to someone in person it's a lot more natural. (3rd 2008)

\section{Discussion}

Students performed better in oral compared with written tests; this result was consistent between year groups, between different types of questions and when using paired and un-paired designs. There are a number of possible explanations for this strong effect, including bias in the assessment procedures. The famous case of 'clever' Hans, 'the counting horse' illustrates the potential influence of unconscious cues from the interviewers (Jackson 2005). Hans was able to 'count' by stamping its hoof until its owner unwittingly signalled when to stop. Such effects may have occurred in our study (although, of course, the current questions were much more complex and less open to simple cues than counting). We agreed with standard interview procedures which excluded explicit prompts and encouragement, but did not curtail all normal social interaction. We were concerned to preserve the "ecological integrity' of the interviews and wanted to avoid the highly artificial circumstance of interviewers simply speaking a question and then remaining silent, like disembodied recorders. Instead the experience was designed to be much closer to an authentic viva voce or job interview. The current study was therefore not designed as tightly controlled psychological research, but rather as a comparison of oral and written assessments under realistic educational settings. As such, the possible existence of 'clever Hans effects' can be regarded as an integral part of most oral assessments, in the same way that the ability to write legibly and quickly is integral to most written assessments. There were no a-priori expectations that the oral performances would be better; in fact, given the suggestions that oral assessments can lead to bias against certain groups of students and can induce stress, a significantly worse performance seemed equally likely.

The current work supports the evidence that oral assessments might induce more anxiety than written ones. The quantitative comparison approached significance (Figure 2), and anxiety was an important theme raised in the qualitative responses. However this is not necessarily negative, indeed it may explain the better average performance, with students preparing more thoroughly than for a 'standard' assessment. Interestingly a majority of the third-year students, who chose to identify anxiety as a feature of the oral assessment, nevertheless stated that they preferred it to a written test. In his phenomenographic study of student experiences of oral presentations, Joughin (2007) found that greater anxiety about oral compared with written assessment was associated with a richer conception of the oral task as requiring deeper understanding and the need to explain to others. Thus anxiety was a product of deeper and more transformative learning. The reported anxiety might also simply reflect the relative lack of experience in oral compared with written assessments, which was a point made explicitly in the qualitative evaluation:

I think the oral is quite different from the writing and we should have some training because we don't have experience. (3rd 2008) 
As with all types of assessment, it is likely that oral examinations will suit some learning styles and personalities better than others. It is not surprising that students with dyslexia might favour oral assessments (Waterfield and West 2006). The current research lends qualitative support to this idea, with two first-year students identifying dyslexia as the reason why they chose to swap from the written to the oral group and students raising the issue in the evaluation:

Before we actually did the [written] test I was a bit apprehensive as I have really bad spelling so I do get quite conscious about that. (1st 2008)

I think I performed to a higher standard than in written tests. The reason for this I have dyslexia, and dyspraxia, so reading and writing for me has always been harder than just plain speak. (3rd 2007)

However, there is no support here for the notion that oral assessments should be regarded as somehow marginal or suited only for 'special' groups of students. Although sample sizes were not sufficiently large to allow multiple sub-divisions into different social and demographic groups, there was no evidence that particular types of students did worse at orals. Although the discrepancy in mean marks obtained in oral compared with written tests was not as large for male as for female students, the trend was the same and the lack of significance may have been a result of lower sample sizes. Clearly it would be interesting to investigate possible gender differences further, but our results do not suggest males would be disadvantaged by using oral assessments.

Because oral language may generally carry a bigger 'emotional charge' than written (Carter 2008), and of course is supplemented in most cases with a range of body language that can transmit emotional messages, it may be true that oral assessment will be better fitted to affective and reflective tasks. In contrast the enunciation of complex abstract ideas might be easier in writing; a clear example would be mathematics. These arguments might suggest the promotion of oral assessments specifically for developing and measuring reflective skills, whilst abstract conceptual thinking should be assessed using traditional written formats. However, the current work showed no such distinction. The first-year cohorts were tested on theoretical, abstract ideas such as 'the argument from design' and aspects of nitrogen cycling in ecosystems, and yet, students performed better on these questions when responding orally. The third-year students were assessed on questions divided into 'scientific analysis' and 'personal and professional development' categories, but a similar result of better performance in the oral compared with written responses was found for both. Hence there is no support here for the idea of restricting oral assessments to 'special' or emotional categories of learning. The Third International Mathematical and Science Study (TIMMS) programme tested thousands of children using the same standard written tests in different countries to allow international comparisons. Schoultz, Säljö, and Wyndhamn (2001) interviewed 25 secondary school children using two TIMMS questions on physics and chemistry concepts. They found much better performance in the oral tests than the average scores in the written tests for children of the relevant age; their qualitative analyses showed that their subjects often understood the core concepts being tested but failed to interpret the written questions correctly without guidance. Hence the ability to re-phrase the question in an oral setting allowed a genuine test of students' conceptual understanding, and thus better performance. A similar 
effect may explain some or all of the differences we found, and we endorse their recommendation to challenge the often implicit assumption that 'responding to abstract questions in writing is the natural context in which knowledge appears'.

A long tradition in philosophy and discursive psychology views language as constitutive rather than simply transmissive; people create key aspects of their reality (particularly their social and subjective realities) through language and especially through 'speech acts'. This tradition is concerned with language as a form of social action, which helps construct such attributes as 'the self' during conversation and discourse (Horton-Salway 2007). This discursive approach, related to Barnett's idea of students creating 'pedagogical identities' through speech (Barnett 2007), can help interpret an important theme in the experiences reported by the students concerning the performative aspects of the viva. One reason students reported greater anxiety was because they were 'performing' in a social space:

This experience has taught me that it is really important to prepare as much as possible for an interview. There is a big difference between going over things in your head and saying them out loud clearly and confidently. (3rd 2007)

There was a perception that the oral interview required a different approach from a written test:

I think that an oral exam allows people to use grammar and words that they may not use when writing. (3rd 2007)

With a lot of written assessments, I think, you just memorise the paragraph like a parrot and not know what it means. But you can tell when someone is doing that when you speak to them because they get that glazed look in their eyes as they recite it. (1st 2008)

This different approach was seen as being more 'professional':

I felt uncomfortable and was concentrating so hard on trying to sound professional and not make mistakes. This is why I was reluctant to use the word 'niche', I thought $95 \%$ that it was the correct word to use. (3rd 2007)

There is an impression here of students striving to create 'professional' and 'confident' personalities (Gent, Johnston, and Prosser 1999). Zadie Smith describes one of her working-class characters using the words 'modern' and 'science': 'as if someone had lent him the words and made him swear not to break them' (2000, 522); the oral assessments involved students using professional language without 'breaking it'.

Written examinations do not seem to elicit the same feelings, perhaps because such examinations are so strongly identified with the worlds of school and college, rather than work, and perhaps because they are usually private and anonymous:

Because we have done [written assessments] since we have been in school, its normal for us but once you leave school/education you will never need [to do them] again whereas talking to somebody you will always use. (3rd 2008)

Whilst most academics recognise how assessments can drive student learning, they may not appreciate how the mode of assessment - including the 'social performance' of the assessment - may shape students' approaches and even identities. 
In her discussion of the power of the spoken word in the ancient world, Karen Armstrong describes Socrates' low opinion of the written text compared with the vivifying effect of living dialogue: 'Written words were like figures in a painting. They seemed alive, but if you questioned them they remained "solemnly silent". Without the spirited interchange of a human encounter, the knowledge imparted by a written text tended to become static' $(2009,64)$. There is a sense of fluidity, of students 'trying things out' during the interchange of the oral assessment - this exploration might be of identities but also of concepts such as 'niche'. This stands in contrast to the 'static' representation in written assessments, and is a powerful endorsement of the use of oral assessments. The current work has found no evidence of disadvantage accruing from oral assessments to particular groups of students, nor of the need to restrict orals to particular types of questions. Rather our quantitative and qualitative results suggest important benefits to students from their use. Our sample size was relatively small and was restricted to biology students at a single institution; if our results prove representative of broader groups of students, then they support attempts to uphold and enhance the 'spirited interchange' of the oral as a form of assessment in higher education.

AQ5 Notes on contributors

\section{References}

Armstrong, K. 2009. The case for god: What religion really means. London: Bodley Head. Barnett, R. 2007. A will to learn: Being a student in an age of uncertainty. Maidenhead: McGraw-Hill/Open University Press.

Campbell, F., L. Beasley, J. Eland, and A. Rumpus. 2007. Final report of Hearing the student voice project: Promoting and encouraging the effective use of the student voice to enhance professional development in learning, teaching and assessment within higher education. Edinburgh: Napier University. www.napier.ac.uk/studentvoices/download/ Final_report_studentvoice_web.pdf.

Carter, M. 2008. Frege's writings on language and the spoken word. http://western-philosophy. suite101.com/article.cfm/freges_writings_on_language_and_spoken_word\#ixzz0HgAdX 4PI\&D (accessed December 13, 2009).

Gent, I., B. Johnston, and P. Prosser. 1999. Thinking on your feet in undergraduate computer science: A constructivist approach to developing and assessing critical thinking. Teaching in Higher Education 4, no. 4: 511-22.

Hayes, J. 2009. Who is it that can tell me who I am? London: Constable.

Horton-Salway, M. (ed.). 2007. Social psychology: Critical perspectives on self and others. Milton Keynes: Open University Press.

Hounsell, D., N. Falchikov, J. Hounsell, M. Klampfleitner, M. Huxham, K. Thompson, and S. Blair. 2007. Innovative assessment across the disciplines: An analytical review of the literature. York: Higher Education Academy.

Jackson, J. 2005. Clever hans. A horses tale. http://www.skeptics.org.uk/article.php?dir= articles\&article=clever_hans.php (accessed January 15, 2010).

Joughin, G. 1998. Dimensions of oral assessment. Assessment \& Evaluation in Higher Education 23: $367-78$.

Joughin, G. 2007. Student conceptions of oral presentations. Studies in Higher Education 32, no. 3: 323-36.

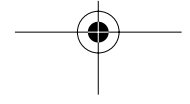


Lloyd, P., A. Mayes, A. Manstead, P. Meudell, and H. Wagner. 1984. Introduction to psychology. An integrated approach. London: Fontana.

Schoultz, J., R. Säljö, and J. Wyndhamn. 2001. Conceptual knowledge in talk and text: What does it take to understand a science question? Instructional Science 29: 213-36.

Wakeford, R. 2000. Principles of assessment. In Handbook for teaching and learning in higher education, ed. H. Fry, S. Ketteridge, and S.A. Marshall. London: Routledge.

Waterfield, J., and B. West. 2006. Inclusive assessment in higher education: A resource for change. Plymouth: University of Plymouth. http://www.plymouth.ac.uk/pages/view.asp? page $=10494$ (accessed January 15, 2010).

Wisker, G. 2004. Developing and assessing students' oral skills. Birmingham: Staff Education and Development Association. 